\title{
La renovación de la arquitectura religiosa en Cerdeña durante los siglos XVI y XVII
}

The Renewal of Religious Architecture in Sardinia during $16^{\text {th }}$ and $17^{\text {th }}$ Centuries

\section{Eloy Bermejo Malumbres ${ }^{1}$}

Instituto de Estudios Riojanos

Resumen: La arquitectura religiosa en Cerdeña experimentó durante los siglos XVI y XVII una gran transformación en sus edificios religiosos que ha hecho necesario resaltar sus peculiaridades y analizar los clichés interpretativos a los que se ha visto sometida. La identificación de las posibles diferencias existentes entre norte y sur de la isla ha permitido comprobar los diferentes caminos por los que se desarrolló el fenómeno consistente en cubrir las naves de los templos con modernas bóvedas pétreas y la aparición de las cúpulas.

Palabras clave: Cúpulas, bóvedas, Cerdeña, arquitectura, renovación

Abstract: During the sixteenth and seventeenth centuries, religious architecture in Sardinia suffer a great transformation in its religious buildings, which made it necessary to stand out its peculiarities and to analyze the interpretative cliché to which it has been subjected. The identification of the possible differences between north and south of the island has allowed to verify the different ways by which the phenomenon was developed to cover the ships of the temples with modern stone vaults and the appearance of the domes

Key Words: Domes, vaults, Sardinia, architecture, renewal

\footnotetext{
${ }^{1}$ https://orcid.org/0000-0003-2614-6641
}

(C) 2017 Philostrato. Revista de Historia y Arte 


\section{La Ilegada de las cubiertas pétreas en el siglo XVI: bóvedas de terceletes}

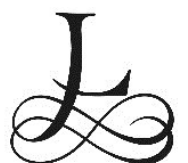

a reconversión en piedra de las antiguas cubiertas de madera de los templos religiosos en Cerdeña que comenzó a partir de la primera mitad del siglo XVI en una serie de casos aislados, presentó una continuidad a partir de la segunda mitad del siglo.

A partir de los años sesenta del siglo XVI comenzaron a aparecer las bóvedas de terceletes, una solución que se difundió en la zona centromeridional de Cerdeña principalmente para cubrir espacios aislados, como presbiterios y capillas, y que posteriormente llegó a emplearse para cubrir las naves de los templos en forma de sucesión de tramos, sustituyendo así a las viejas cubiertas de madera ${ }^{2}$. De hecho, en Cerdeña dos de los primeros edificios que emplean las bóvedas de terceletes para cubrir la nave en esta primera mitad de siglo son la iglesia de Santa Eulalia en Cagliari y la catedral de Iglesias [fig. 1].

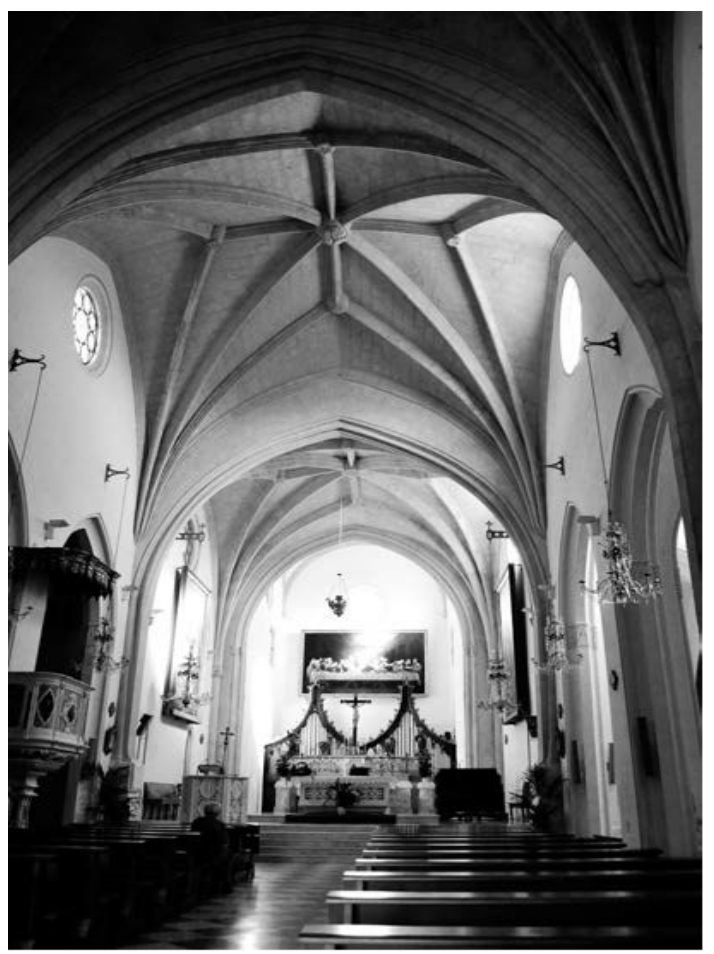

Fig. 1. Cagliari, iglesia parroquial de Santa Eulalia (Foto: Federico Maria Giammusso)

En el curso de la segunda mitad del siglo XVI, la tendencia a cubrir los edificios medievales con modernos sistemas en piedra fue la tónica general de muchos territorios de la Monarquía hispánica. En Cerdeña, la situación política estable y el incipiente crecimiento económico por el que se atravesaba en este periodo ayudó a la difusión del fenómeno. La necesidad de disponer

\footnotetext{
2 Marcello Schirru, "Forme e modelli architettonici tra la Spagna e la Sardegna del '500", ArcheoArte. Rivista elettronica di archeologia e arte, 2, (2013), pp. 281-298, espec. p. 287.
} 
de un edificio moderno y adecuado para la época empujó a los constructores locales a transformar radicalmente los edificios medievales. En el caso sardo, se optó por la conservación de las estructuras medievales preexistentes, ya que generalmente los recursos económicos no eran excesivamente notables y no permitieron realizar grandes intervenciones de reconstrucción por lo que se retrasó su implantación mediante la construcción de arcos diafragma que, provisionalmente preparaban la nave para una futura construcción en piedra. Cuando pudieron llevarse a cabo, las intervenciones se limitaron frecuentemente $a$, por un lado, obras de ampliación, como fueron la construcción de capillas, campanarios, sacristías y coros altos, y por otro lado a trabajos de reforma, a través de la sustitución de las antiguas techumbres de madera por bóvedas pétreas. No obstante, también se construyeron edificios de nueva fundación, limitados a las pocas obras patrocinadas por Felipe II, como la iglesia de San Agustín nuevo en Cagliari ${ }^{3}$, o a los complejos fundados por la Compañía de Jesús, como colegios y casas profesas ${ }^{4}$.

El objetivo que se persiguió, fue la transformación del espacio interior de los edificios religiosos, a través de la sustitución de los antiguos sistemas de

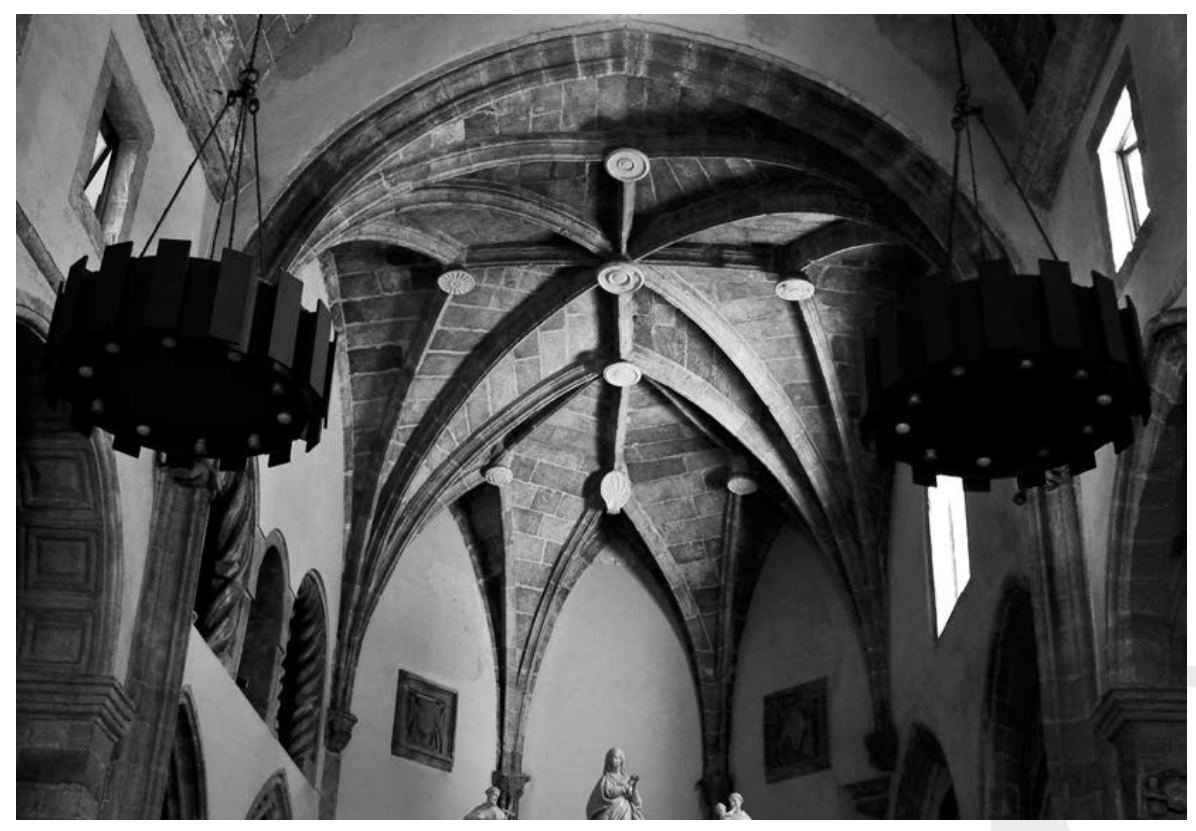

Fig. 2. Alghero. iglesia conventual de San Francisco. Bóveda del presbiterio (Foto: Federico Maria Giammusso)

cubierta de las naves con nuevos sistemas en piedra con bóvedas de crucería, a menudo reutilizando los arcos diafragma de las estructuras preexistentes. En el sur de la isla, el uso de las bóvedas de terceletes, como en las ya citadas iglesias de Santa Eulalia y Santo Domingo en Cagliari o en la catedral de

${ }^{3}$ Sobre la iglesia de San Agustín nuevo, Francesca Segni Pulvirenti y Aldo Sari, Architettura tardogótica e d'infusso rinascimentale, (Nuoro: Illiso, 1994), p. 200.

4 Para una panorámica sobre las fundaciones de los jesuitas en Cerdeña, Emanuela Garofalo, "Le architetture della Compagnia di Gesù in Sardegna (XVI-XVIII secolo)", en La arquitectura jesuítica, coords: María Isabel Álvaro Zamora, Javier Ibáñez Fernández y Jesús Criado Mainar, (Zaragoza: Universidad de Zaragoza, 2010), pp. 141-192. 
Iglesias, fue probablemente reinterpretado a favor de un nuevo concepto de espacio religioso más cercano a los postulados del clasicismo y derivado de las necesidades litúrgicas que surgieron tras Trento. El lenguaje clasicista se fue aplicando en elementos más o menos aislados, así como paralelamente ocurría en las regiones del Reino de Aragón, donde tal y como ha sido documentado por Javier Ibáñez Fernández, desde mediados del siglo XVI y los primeros años del Seiscientos, el sistema constructivo gótico y particularmente las bóvedas de crucería, llegaron a entenderse como un sistema plenamente clásico, por lo que podían perfectamente coexistir con elementos del lenguaje clasicista, cada vez más presente en la isla ${ }^{5}$. Los elementos de la estructura comenzaron a reinterpretarse en clave clásica y, concebidos como molduras, fueron susceptibles de trabajarse al romano ${ }^{6}$.

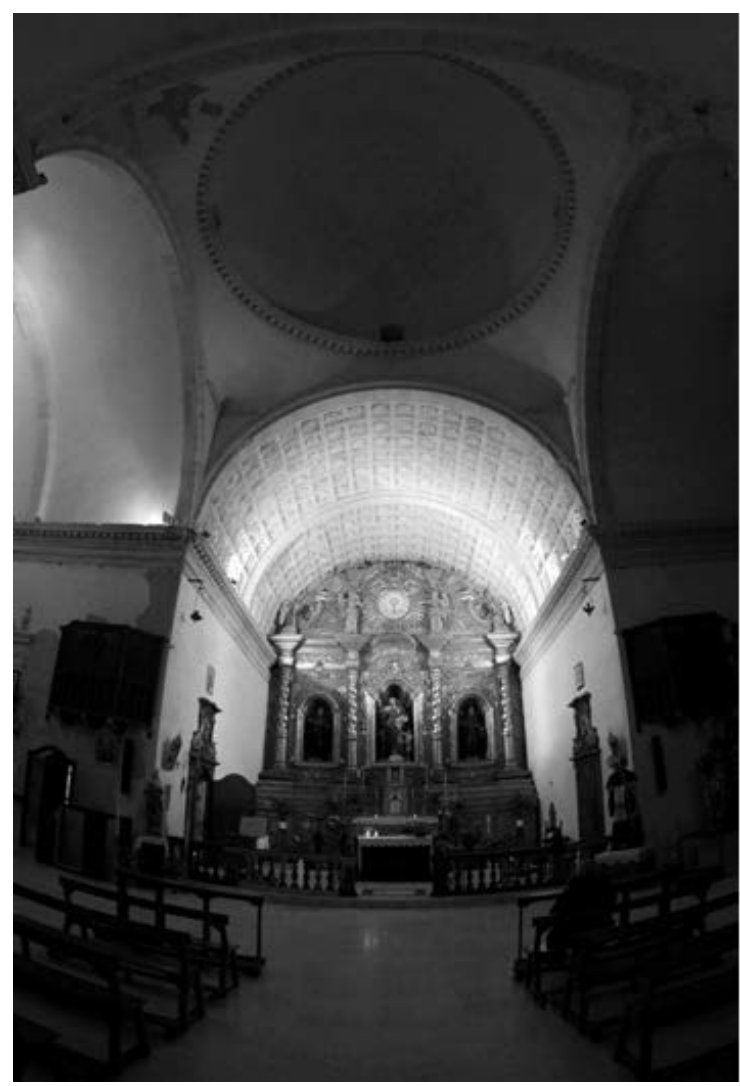

Fig. 3. Cagliari. Iglesia conventual de San Agustín nuevo. Cúpula y presbiterio

Los edificios sardos cubiertos en la totalidad de la nave con bóvedas de crucería parecen responder a una expresión local de un tema que en el curso de la segunda mitad del siglo XVI tuvo una serie de ejemplos paralelos en el Reino de Aragón?. Ante la ausencia de referencias documentales que

\footnotetext{
5 Javier Ibáñez Fernández, "La arquitectura en el reino de Aragón entre el gótico y el renacimiento", Artigrama, 23, (2008), pp. 39-95, espec., p. 55.

${ }^{6}$ Ibáñez, "La arquitectura en el reino...", p. 56.

7 Sobre el paralelismo entre los ejemplos sardos y aquellos aragoneses, remitimos a Federico María Giammusso, "Il Convento di San Domenico a Cagliari", (Tesis de Doctorado en Storia dell'architettura e conservazione dei beni architettonici XXIV Ciclo, Università degli Studi di Palermo, 2015).
} 
permitan relacionar los casos sardos con el contexto aragonés, es plausible que, ante un problema estructural, la solución que se encontró fuese la misma, aunque se tratara de territorios lejanos, ya que este tipo de bóvedas habían sido perfectamente asimiladas por los picapedrers ${ }^{8}$. Concretamente, en el caso sardo, ante intervenciones que consistieron exclusivamente en la sustitución de las cubiertas, el sistema de las bóvedas de terceletes con cinco claves permitió cubrir espacios mayores, respecto a los sistemas de bóvedas con una clave o de medio cañón, y permitió una mayor flexibilidad operativa, ya que estas bóvedas se adaptaron mejor a los tramos irregulares de la nave ${ }^{9}$.

A diferencia de lo que ocurrió en el sur, en el norte de la isla, las bóvedas de terceletes no gozaron del éxito que alcanzó en la zona centro-meridional de la isla (tan sólo se conocen los ejemplos de la iglesia de San Francisco de Alghero y la iglesia de Pozzomaggiore) [fig. 2]; no obstante, en este momento los edificios religiosos de la zona septentrional se limitaron a cubrir sus espacios con bóvedas de crucería simple y contemporáneamente, en la ciudad de Sassari, algunos edificios como la catedral y posteriormente la iglesia de la Compañía de Jesús comenzaron a adoptar la cúpula para cubrir el espacio del crucero de los templos, lo que supuso, posiblemente, una alternativa a las bóvedas de terceletes en la zona septentrional de la isla.

\section{La aparición de las cúpulas en Cerdeña}

A partir de la segunda mitad del siglo XVI las cúpulas parecen concentrarse en la ciudad de Sassari a excepción de la cúpula levantada mediante trompas a partir de 1580 en la iglesia de San Agustín de Cagliari ${ }^{10}$ [fig. 3] y de la hoy desaparecida iglesia de Santa Lucia en la Marina, también en Cagliari ${ }^{11}$. No obstante, el primer caso conocido pero que presenta algunas características originales, es la "bóveda de platillo"12, sobre trompas, con nervios de crucería del ingreso a la torre campanario de la catedral de Alghero, que podría datarse en torno a los años cuarenta o cincuenta del Quinientos ${ }^{13}$. En realidad, esta solución no parece estar en relación con los ejemplos sasareses de la cúpula de la catedral, la cúpula de la iglesia de Gesù e María de la

\footnotetext{
8 Marià Carbonell i Buades, "De Marc Safont a Antoni Carbonell: la pervivencia de la arquitectura gótica en Cataluña", Artigrama, 23, (2008), pp. 97-148, espec., p. 105.

9 Giammusso, "Convento di...", p. 257.

${ }^{10}$ Segni Pulvirenti et al., Architettura tardogótica e d'infusso, p. 200.

${ }^{11}$ La solución cupulada empleada en la iglesia de Santa Lucia presenta numerosas analogías con la cúpula levantada en la iglesia de San Agustín Nuevo de Cagliari, aunque el paso del cuadrado al octágono resulta diferente, mientras en el primer ejemplo se utilizaron pechinas, en el segundo se emplearon las trompas; Marco Cadinu, "Il rudere della chiesa di Santa Lucia alla Marina di Cagliari. Architettura, archeologia e storia dell'arte per il recupero di un luogo della città medievale", ArcheoArte. Rivista elettronica di archeologia e arte, Supplemento al no 1, (2012), pp. 543-575.

12 Arturo Zaragozá, "Arquitecturas del gótico mediterráneo" en Una arquitectura gótica mediterránea, dir. Eduard Mira, Arturo Zaragozá, (Valencia: Genaralitat Valenciana, Conselleria de Cultura i Educació, 2003), p. 153. Vandelvira la llama "capilla redonda en vuelta redonda".

13 Marco Nobile, "La cattedrale di Alghero. Note e ipotesi sul primo progetto", Lexicon. Storie e architetura in Sicilia e nel Mediterraneo, 14-15, (2012), pp. 26-27.
} 
Compañía de Jesús (actual Santa Caterina) o la que podemos encontrar en una capilla de la iglesia de la Virgen de Valverde.

Gracias a la aparición de nuevos documentos de archivo y a una relectura de los ya existentes, permiten plantear la posibilidad de que la cúpula de la catedral de Sassari fuera la primera construida en la isla [fig. 4]. La historio-

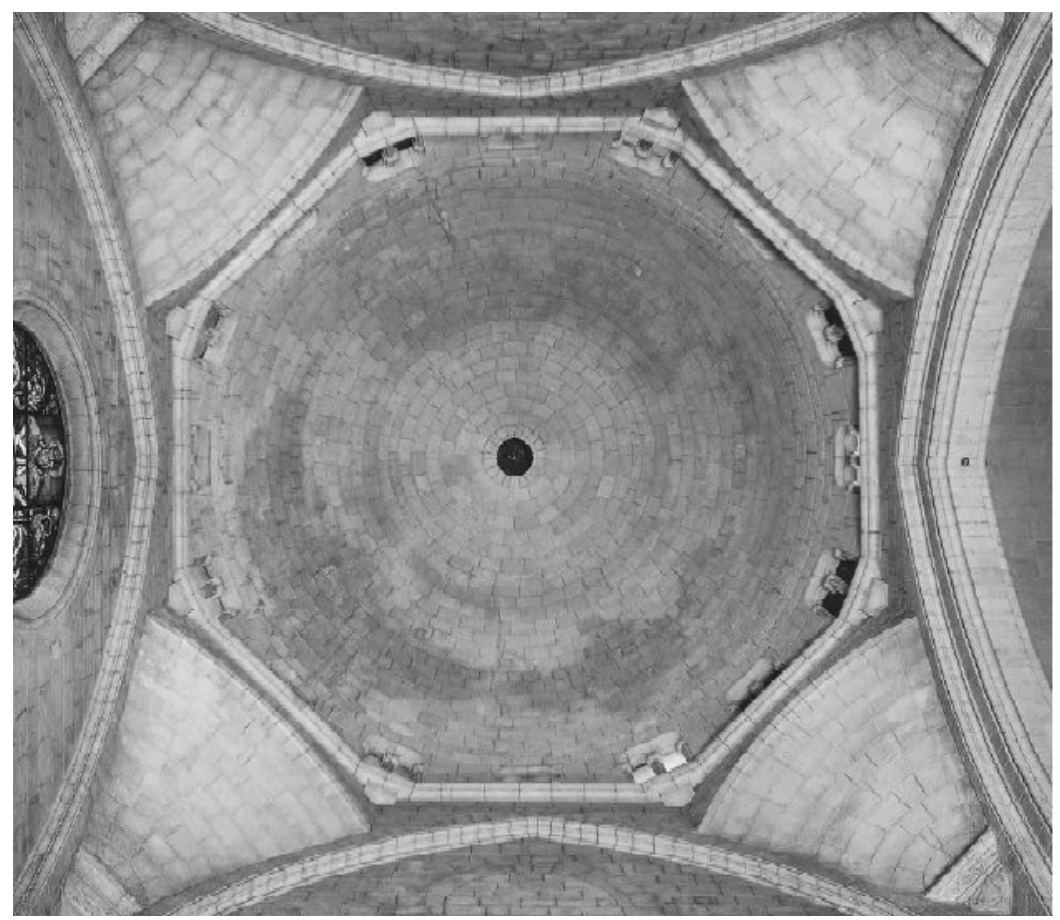

Fig. 4. Sassari. Cúpula de la catedral (Foto: Marisa Porcu Gaias)

grafía ha sugerido diferentes fechas sobre su realización; por un lado, en 1585 el canónigo y posteriormente arcipreste Giovanni Francesco Fara se refiere a ampliaciones en la catedral a partir del año 1480, aunque no especifica concretamente si afectaron a la construcción de la cúpula, probablemente porque ésta se encontraba ya construida en el año en el cual escribía, puesto que su vuelta a Sassari se produjo en 1568 y no indica trabajos sobre la misma ${ }^{14}$. Por otro lado, Marisa Porcu Gaias ${ }^{15}$ ha propuesto recientemente que la cúpula se realizó en las primeras décadas del siglo XVI, a partir de las noticias aportadas por Vittorio Angius donde refiere que la iglesia fue ristaurata nel 1531 nelle volte e nella cupola ${ }^{16}$. En realidad, las noticias aportadas por Angius son bastante dudosas, sobre todo porque no

\footnotetext{
${ }^{14}$ En 1585 Giovanni Francesco Fara, nombrado arcipreste de la diócesis Turritana en 1578, escribía que en el "anno 1480 populi expensis in ampliorem formam, qua est hodie, redactum insignique testudine et sacellis multis ornatum"; Giovanni Francesco Fara, In Sardiniae Chorographiam, ed. Enzo Cadoni, (Sassari: Gallizzi, 1992), pp. 61-229.

${ }_{15}$ Sobre la renovación de la catedral de Sassari entre los siglos XV y XVIII se vea: Marisa Porcu Gaias, Sassari. Storia architettonica e urbanistica dalle origini al '600, (Nuoro: Ilisso, 1996), pp. 87-88 y 126131; Eloy Bermejo, "La catedral de Sassari y la arquitectura religiosa en Cerdeña entre los siglos XVI y XVIII", (Tesis de Doctorado en Analisi, rappresentazione e pianificazione delle risorse territoriali, urbane, storiche-architettoniche e artistiche XXV Ciclo, 2016).

16 Vittorio Angius, "Sassari", en Dizionario geografico storico-statistico-commerciale degli Stati di S.M. il Re di Sardegna, dir. Goffredo Casalis, (Torino, 1849), pp. 71-375, espec., p. 259 y 290.
} 
menciona referencias documentales en su trabajo que permitan cotejar los datos y porque un documento con fecha 1549 indica que en ese año se estaban todavía realizando trabajos en las estructuras de conexión de la catedral, coincidiendo con la recuperación del proyecto de reforma del edificio tras la visita del emperador Carlos $V$ a la isla en 1541, lo que pudo dinamizar la actividad económica favoreciendo la celebración del Parlamento en 1543

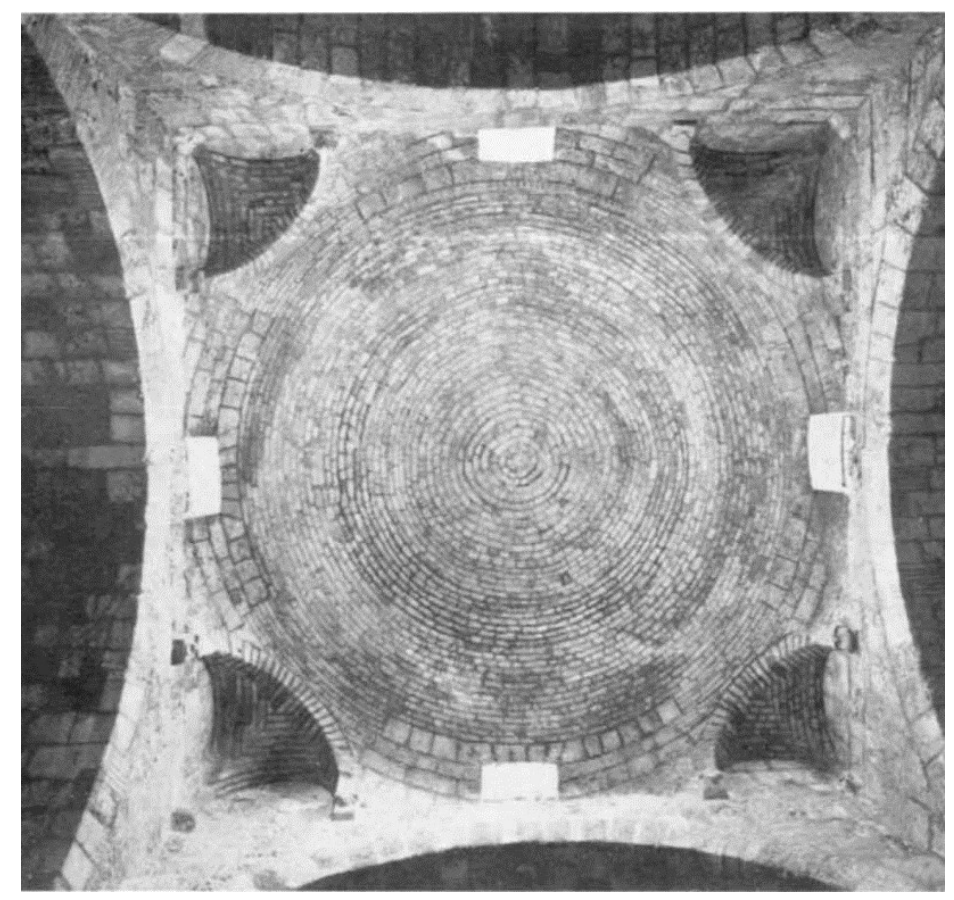

Fig. 5. Cagliari, iglesia de San Saturnino. Cúpula (Foto: Raffaello Delogu)

por parte del virrey Antonio Folch de Cardona. En este Parlamento se decidió destinar una importante suma de dinero para mejorar el sistema defensivo y dar conclusión a aquellos edificios que habían quedado incompletos como la catedral de Alghero y la catedral de Sassari ${ }^{17}$.

Es bastante probable que, junto con Antonio Folch de Cardona, quién desarrollase un papel importante en la reanudación de los trabajos en el edificio catedralicio de Alghero a partir de los años cuarenta del Quinientos, y en la construcción de la iglesia de San Francisco de la misma ciudad fuera Pedro Baguer ${ }^{18}$. La figura de Baguer debió de resultar decisiva también en la reforma de la catedral de Sassari, ya que el 21 de febrero de 1549, el capítulo pidió al sasarés Giovanni María, maestro de los franciscanos observantes en la ciudad de Cagliari, que intercediese por el capítulo sasarés ante el recién nombrado Presidente del Reino, Pedro Baguer ${ }^{19}$, para que destinase una

17 Eduard Toda i Güell, Cortes españolas de Cerdeña, (Cagliari: Arxiu de Tradicions de L'Alguer, 2009), p. 43. En el documento, perteneciente a las Cortes de Don Antonio de Cardona de 1543, el Emperador Carlos $\checkmark$ realizó un donativo de cien mil escudos, de los cuales cuarenta mil debían invertirse en reparaciones. 18 Segni Pulvirenti et al., Architettura tardogótica e d'infusso, p. 119.

19 Pedro Baguer era obispo de Alghero, y tras la marcha del virrey Antonio Folch de Cardona, en 1549 fue nombrado Presidente del Reino hasta el nombramiento de un nuevo virrey. En la catedral de Jaca se encuentra el monumento funerario de Pedro Baguer, realizado por el escultor mallorquín Guillén Salbán, 
cantidad de dinero para acabar de inlasar la dita $s e u^{20}$. El término inlasar hace referencia a estructuras de conexión ${ }^{21}$, por lo que es posible que se estuviese trabajando en la sustitución de los antiguos arcos diafragma de la iglesia por modernas estructuras pétreas, entre las que se encontraría la cúpula, que pudo acabarse antes de los años setenta del siglo 22 .

La cúpula de la catedral de Sassari se presenta al exterior parcialmente extradosada sobre un paralelepípedo, sin tambor, y con cuatro potentes contrafuertes en sus ángulos ${ }^{23}$. En su interior, la cúpula circular se levanta sobre pechinas y está rodeada por una serie de ventanas bíforas que permiten el paso de la luz desde el exterior al interior del templo. Llama la atención la ausencia del tambor, por lo que la cúpula emerge directamente del paralelepípedo, una solución que parece seguir modelos de origen bizantino que se originaron en el Mediterráneo durante la Edad Media ${ }^{24}$ y que en Cerdeña se encuentran por citar algunos, en la iglesia de San Saturnino de Cagliari [fig. 5], la iglesia de San Juan de Sinis en Cabras, el santuario de Bonacardo en Cabras, la iglesia de San Juan de Assemini, la iglesia de Santa María de Cossoine o la parroquial de Sant'Antioco ${ }^{25}$. Durante el siglo XVI, en otra gran isla del Mediterráneo, Sicilia, los promotores comienzan a requerir estructuras a la antigua a los constructores formados en la tradición medieval que buscan respuestas en soluciones del pasado normando o bizantino ${ }^{26}$. La fascinación de los maestros constructores y de las personas con mayor formación intelectual de la época por aquellos edificios que habían conseguido sobrevivir a lo largo de la historia, entre los que cabe destacar un gran número de cúpulas hemisféricas adosadas a cuerpos arquitectónicos prismáticos cuadrados o poligonales, como las que podemos observar en la Capilla Palatina del Palacio Normando de Palermo o la iglesia de Santa María dell'Ammiraglio en la misma ciudad, o fuera de la capital siciliana, en la iglesia de la Santísima Trinidad de Delia, en Castelvetrano, generaron un gran interés por sus estructuras, el estudio detallado y el conocimiento de estas obras de época medieval así como la presencia de técnicos experimentados como Antonio Belguardo, permitió en los primeros años del siglo XVI una reinterpretación de estas estructuras ${ }^{27}$.

entre 1567-1569. Se vea al respecto: Javier Ibáñez, "Renacimiento a la francesa en el Quinientos aragonés", Artigrama, 22, (2007), pp. 473-511, espec., pp. 507-508.

20 Archivio Storico Diocesano Sassari, Serie G 3, c. 43v.

${ }^{21}$ Pietro Casu, Vocabolario sardo logudorese - italiano, ad vocem: "it: legare; sp: lazo, enlazar", (Nuoro: Ilisso, 2003); Miquel Fullana, Diccionari de l'art i dels oficis de la construcció, ad vocem: "fer que dos o més elements d'obra quedin travats o lligats uns ambs els altres", (Palma de Mallorca: Institut Moll, 2005).

22 Marco Nobile, "Volte in pietra. Alcune rifessioni sulla stereotomia tra Italia meridionale e Mediterraneo in età moderna", en La stereotomia in Sicilia e nel Mediterraneo, dir. Marco Nobile, (Palermo: Edizioni Caracol, 2013), p. 27.

23 Emanuela Garofalo, "New architectural models and building tradition, a dialogue in early modern Sardinia. The Jesuit church in Sassari", International Journal of Architectural Heritage, 9, (2015), pp. 143156.

${ }^{24}$ Garofalo, "New architectural models and building...", pp. 143-156.

25 Sobre estos edificios se remite a: Raffaello Delogu, L'architetura del Medioevo in Sardegna, (Sassari: Carlo Delfino editore, 1988).

${ }^{26}$ Nobile, "Volte in pietra. Alcune rifessioni...", p. 18.

27 Garofalo, "New architectural models and building...", p. 147. 


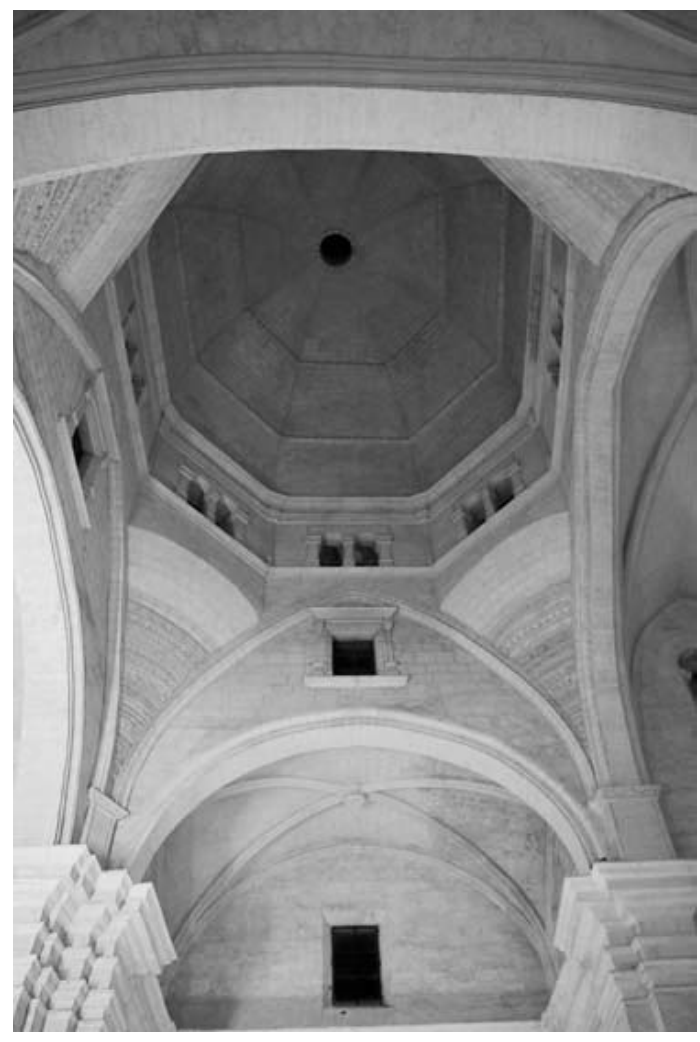

Fig. 6. Sassari, iglesia Gesù e Maria. Decoración pechinas. (Foto: Emanuela Garofalo)

Las relaciones entre las dos islas parecen haberse producido desde finales del siglo XV, tal y como parecen confirmar las noticias documentales que han sido exhumadas en diferentes archivos sicilianos, donde varios maestros sardos aparecen implicados en la construcción de espacios arquitectónicos sicilianos dotados con cúpula, como la presencia en 1529 del maestro Giordano de Cagliari en la ciudad de Palermo para construir una cúpula en la capilla Aiutamicristo en la iglesia de Santo Domingo de Palermo, o los ayudantes sardos como Diego Cossu que trabajaron bajo la dirección del maestro Antonio Belguardo, experto en la construcción de cúpulas en los primeros años del siglo XVI en la ciudad de Palermo ${ }^{28}$. Las soluciones empleadas por Belguardo en Sicilia, muestran una evidente derivación de modelos normandos ${ }^{29}$, sobre todo en el empleo de estructuras con nichos en los ángulos que permiten el paso del cuadrado al octógono y en los pequeños elementos que permiten la unión del espacio octogonal con la circunferencia ${ }^{30}$.

En realidad, en los ejemplos sasareses se encuentran mayores similitudes con modelos presentes en la Sicilia oriental, donde se realizaron originales variantes de las cúpulas realizadas en ciudades como Palermo, sobre todo visible en las pechinas y en la definición geométrica de las cúpulas, en un

${ }^{28}$ Nobile, "Volte in pietra. Alcune rifessioni...", p. 18, 29 y 30.

${ }^{29}$ Sobre el desarrollo de la cúpula en Sicilia consúltese: Maria Giuffrè, "Architettura in Sicilia nei secoli XV e XVI: le cappelle a cupola su nicchie fra tradizione e innovazione", Storia architettura, s.n., 2, (1996), pp. 33-48; Marco Nobile, Un altro rinascimento. Architettura, maestranze e cantieri in Sicilia, 1458-1558, (Benevento: Hevelius, 2002), pp. 86-95; Nobile, "Volte in pietra. Alcune rifessioni...", pp. 18-23;

${ }^{30}$ Nobile, "Volte in pietra. Alcune rifessioni...", pp. 18-23. 
ejercicio de gran conocimiento técnico. Especialmente, las similitudes de los ejemplos sasareses son patentes en la decoración empleada en las pechinas de la capilla Naselli de Comiso, construida a partir de $1549^{31}$. Tanto en la catedral de Sassari ${ }^{32}$, como en la cúpula de la iglesia de la Compañía de Jesús de la misma ciudad ${ }^{33}$, los motivos decorativos de las pechinas son muy similares al del modelo siciliano de Comiso [fig. 6 y 7 ].

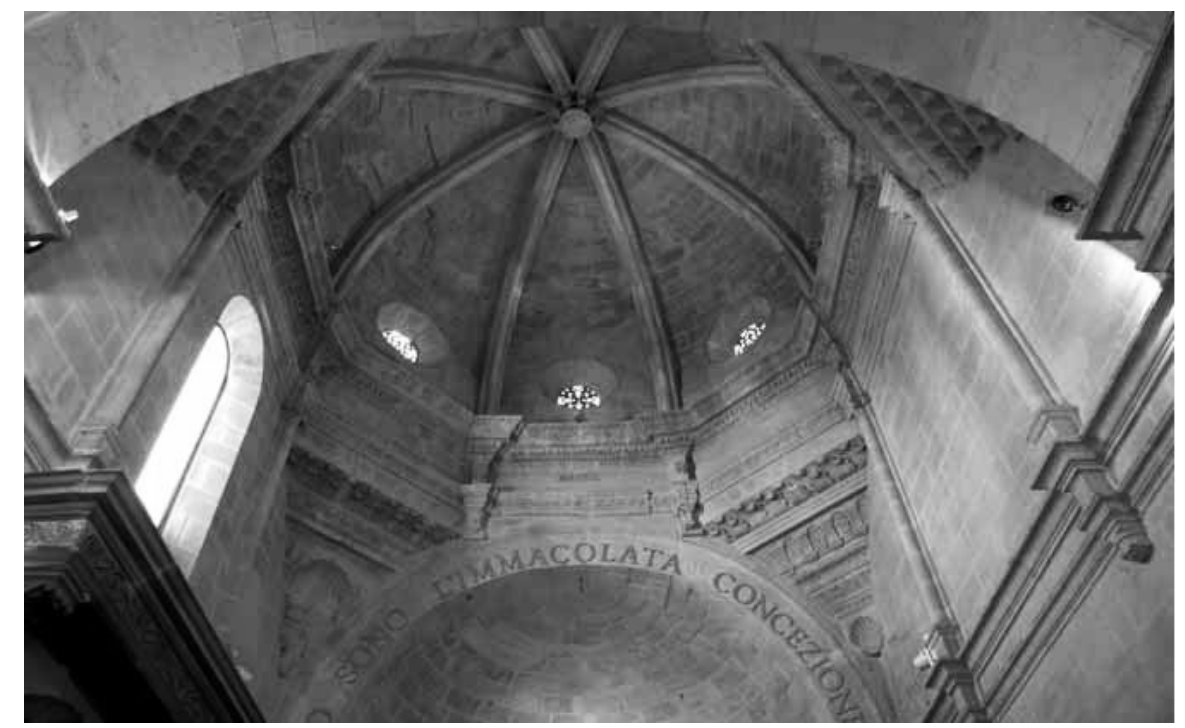

Fig. 7. Comiso (Sicilia), Capilla Naselli. Decoración pechinas (Foto: Marco Nobile)

En la ciudad de Sassari se encuentra otro ejemplo que cuenta con elementos en común a los de la cúpula de la catedral, tanto en su configuración arquitectónica como decorativa, pero se trata solamente de una pequeña cúpula no extradosada situada en la segunda capilla de lado de la Epístola de la iglesia de la Virgen de Valverde, actualmente perteneciente a los padres capuchinos. La historiografía ha considerado que la realización de esta cúpula debió de efectuarse en los últimos años del siglo XVI, coincidiendo con la concesión de la iglesia a los padres capuchinos ${ }^{34}$. Recientemente, Marco Rosario Nobile ha sugerido que la cúpula podría haberse realizado

\footnotetext{
${ }^{31}$ Garofalo, "Le architetture della Compagnia di Gesù...", pp. 155-156; Un reciente trabajo sobre la capilla Naselli en Comiso puede consultarse en: Emanuela Garofalo, "Fra Tardogotico e Rinascimento: la Sicilia sud-orientale e Malta", Artigrama, 23, (2008), pp. 265-300, espec., pp. 279-280; Marco Nobile, "Tra Gotico e Rinascimento: I'architettura negli Iblei (XV-XVI sec.)", en La storia ritrovata. Gli Iblei tra Gotico e Rinascimento, dir. Marco Nobile y Giuseppe Barone, (Comiso: Edizioni Salarchi, 2009), pp. 48-93.

32 Los trabajos de restauración en la catedral de Sassari llevados a cabo el siglo pasado por el arquitecto Vico Mossa han evidenciado que la decoración de las pechinas de la cúpula fue eliminada en el siglo XIX, en su lugar se pintaron las figuras de los cuatro Evangelistas; se vea: Vico Mossa, Restauri nella Cattedrale di Sassari. Relazione letta in Duomo il 2 febbraio 1951, (Sassari-Gallizzi: edizioni Ichnusa, 1951), p. 13; Vico Mossa, Architetture sassaresi, (Sassari: Carlo Delfino editore, 1988), p. 111.

33 Sobre la arquitectura de la Compañía de Jesús en Cerdeña remitimos a: Garofalo, "Le architetture della Compagnia di Gesù...", pp. 143-192; Emanuela Garofalo, "La costruzione di un monumento tra Controriforma e tradizione gotica: la Chiesa dei Gesuiti a Sassari", en AID Monuments. Conoscere Progettare Ricostruire, (Perugia, Roma, 2012), pp. 143-15.

34 Marisa Porcu Gaias ha sugerido que la cúpula se realizó en 1593, año en el que los padres servitas, a los cuales había sido concedida por los consejeros de la ciudad en 1540, la permutaron con la iglesia de San Antonio Abad, perteneciente a los capuchinos desde finales del siglo XVI; véase: Porcu Gaias, Sassari. Storia architettonica e..., pp. 194-197.
} 
contemporáneamente a la cúpula de la catedral, y, por lo tanto, que perteneciese a la anterior iglesia de los padres servitas ${ }^{35}$.

Para el caso sardo, podríamos plantear un proceso similar al que se produjo en la otra gran isla del Mediterráneo. La supervivencia de edificios románicos y las cúpulas que se encuentran en ellos pudo haber sido el modelo en el cual los maestros constructores sardos de la época de los siglos XVI y XVII sigui-

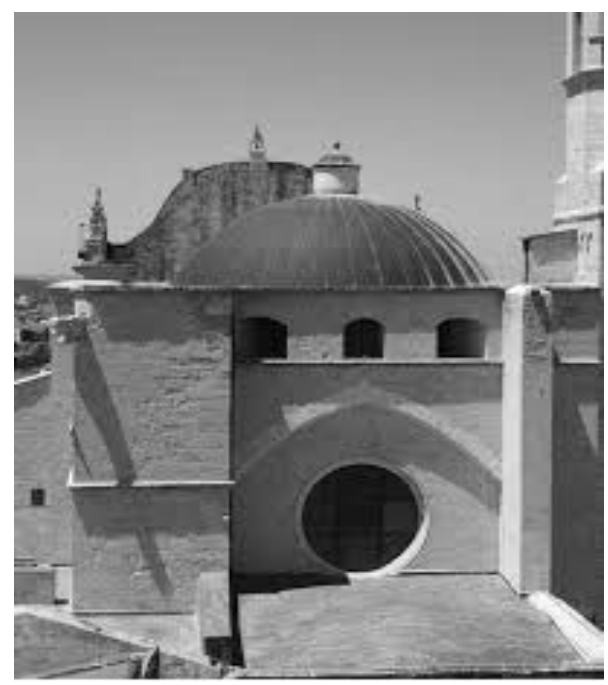

Fig. 8. Sassari. Catedral. Cúpula exterior (Foto: Emanuela Garofalo)

eron para la reinterpretación de las cúpulas. Es posible, que las experiencias adquiridas por los maestros sardos fuera de la isla, como en el caso siciliano, fuesen la base sobre la que, una vez de vuelta a Cerdeña, emprender una renovación tipológica de las estructuras arquitectónicas.

Años más tarde, las soluciones empleadas en la catedral de Sassari permitieron a final de siglo la creación de una variante del modelo de cúpula en la iglesia de Gesù e María de Sassari ${ }^{36}$ [fig. 6]. Las novedades se encuentran en la intención de destacar la cúpula al exterior y en su constitución ochavada. Tanto la cúpula de la catedral como la de la iglesia de los jesuitas de Sassari, presentan una característica particular que ya hemos comentado antes, y es que no poseen tambor [fig. 8]. No obstante, ambas cúpulas presentan algunas diferencias entre sí, por lo que se trataría de casos aislados con ciertas similitudes estructurales y decorativas. Si bien para la cúpula de la catedral hemos planteado similitudes con el entorno siciliano, la del templo jesuita estaría más vinculada a algunos ejemplos presentes en la

35 Con la llegada de los capuchinos se procedió a reformar la iglesia, que debía encontrarse orientada ortogonalmente a la actual iglesia de los capuchinos, por lo que la cúpula podría tratarse en realidad del ábside de la iglesia; ver: Nobile, "Volte in pietra. Alcune rifessioni...", p. 28. Sin excluir esta posibilidad, podría tratarse de la capilla de algún personaje ilustre; la presencia del escudo de los servitas en la clave del tercer tramo podría indicar que la iglesia de los servitas habría mantenido la misma orientación; véase: Porcu Gaias, Sassari. Storia architettonica e..., p. 195.

${ }^{36}$ Un atento estudio sobre la cúpula de la iglesia de la Compañía de Jesús de Sassari y sobre el proceso constructivo de la misma se encuentra en: Garofalo, "Le architetture della Compagnia di Gesù...", pp. 143192; Garofalo, "La costruzione di un monumento...", pp. 143-153. 
Península ibérica en los primeros años de la Edad Moderna influidas por modelos de la Antigüedad romana, especialmente el Panteón de Roma, con un significado probablemente funerario ${ }^{37}$. La mayoría de estos ejemplos se concentran en la ciudad de Sevilla38: en la sacristía mayor de la catedral diseñada por Diego de Siloé y construida en torno a $1542^{39}$; en la Capilla Real de la catedral construida por Hernán Ruiz el Joven entre 1562 y $1575^{40}$ y en la iglesia de la Casa Profesa de la Compañía de Jesús dedicada a la Anunciación y atribuida también a Hernán Ruiz el Joven entre 1565 y $1579^{41}$.

Un interesante ejemplo, con algunas similitudes a la cúpula de la iglesia de Gesù e Maria de Sassari, se encuentra en la capilla Cerralbo en Ciudad Rodrigo, diseñada por el arquitecto Juan de Valencia a partir de $1585^{42}$, donde la cúpula emerge sobre el paralelepípedo sin la utilización del tambor, una solución que posiblemente estuvo determinada por las condiciones estructurales del edificio. A partir de la construcción de la cúpula de El Escorial, la primera en el panorama ibérico que emplea el tambor, y la política artística llevada a cabo por Felipe II, donde se dan cita referencias al lenguaje clásico, los modelos de cúpulas posteriores en el territorio hispánico se vieron influenciados por el ejemplo escurialense. No obstante, la cúpula de la iglesia de Gesú e María de Sassari no parece reproducir ninguno de los modelos mencionados anteriormente.

\section{Cúpulas en el siglo XVII: soluciones innovadoras}

Las dificultades para recaudar los recursos económicos necesarios hicieron que la realización de cúpulas a partir de la segunda mitad del siglo XVI se concentrase en ejemplos aislados y no constituyesen una verdadera alternativa a las bóvedas de terceletes hasta los primeros años del siglo XVII, donde se crearon estructuras cupuladas que parecen conjugar de manera innovadora diferentes modelos, por un lado el uso de bóvedas de peu de Ilantia, presentes en Cerdeña desde los primeros años del siglo XVI, y por otro soluciones ochavadas, configurando de esta manera interesantes ejemplos ${ }^{43}$.

\footnotetext{
37 Agustín Bustamante y Fernando Marías, "La catedral de Granada y la introducción de la cúpula en la España del Renacimiento", Boletín del Museo Camón Aznar, VIII, (1982), pp. 103-115.

38 Otro ejemplo de cúpula trasdosada se encuentra en la iglesia de la Concepción Francisca de La Puebla de Montalbán, cerca de Toledo.

39 Ricardo Sierra Delgado, "La cúpula de la Sacristía Mayor de la Catedral de Sevilla: contexto y evolución en Andalucía" en Actas del Tercer Congreso Nacional de Historia de la construcción, dir. Amparo Graciani García, (Sevilla: Instituto Juan de Herrera, 2000), pp. 1039-1048; Ricardo Sierra Delgado, Diego de Siloé y la nueva fábrica de la Sacristía Mayor de la Catedral de Sevilla, (Sevilla: Universidad de Sevilla, 2012).

40 Alfredo J. Morales, "Sobre la Capilla Real de Sevilla y algunos de sus creadores", Archivo hispalense: Revista histórica, literaria y artística, 227, 74, (1991), pp. 185-196.

${ }^{41}$ Alfredo J. Morales, "La arquitectura jesuítica en Andalucía. Estado de la cuestión" en La arquitectura jesuítica, dir. María Isabel Álvaro Zamora, Javier Ibáñez Fernández, Jesús Criado Mainar, (Zaragoza, 2012), pp. 327-354.

42 Alfonso Rodríguez G. de Ceballos, "La Capilla Cerralbo de Ciudad Rodrigo", Archivo Español de Arte, 190-191, 48, (1975), pp. 190-191 y 199-215; Agustín Bustamante y Fernando Marías, "La sombra de la cúpula de El Escorial", Fragmentos, 4-5, (1985), pp. 46-63; Ana López Mozo, "La huella de El Escorial en las cúpulas españolas de finales del siglo XVI. El caso de la Capilla Cerralbo de Ciudad Rodrigo", Informes de la construcción, Extra-2, 65, (2013), pp. 95-109.

43 Nobile, "Volte in pietra. Alcune rifessioni...", p. 29.
} 
A partir de los primeros años del Seiscientos comenzó a difundirse este tipo de cúpulas, aunque el sistema de bóvedas de terceletes no desapareció completamente, de hecho, se siguió empleando en algunas construcciones ${ }^{44}$. El primer caso donde aparece la cúpula con las características anteriormente mencionadas se encuentra en el presbiterio de la iglesia parroquial de la Virgen Assunta de Selargius, realizada a partir de $1607^{45}$ [fig. 9]. El contrato, que ha sido exhumado por Marcello Schirru, ha permitido resolver un importante vacío historiográfico sobre la arquitectura religiosa sarda de la Edad Moderna, ya que restituye perfectamente el proceso constructivo que se empleó para llevar a cabo la cúpula ochavada con bóvedas de peu de Ilantia, una configuración presente solamente en el contexto sardo ${ }^{46}$.

El contrato fue acordado el 15 de junio de 1607 por Antonio Tola (canónigo de la catedral de Cagliari) y Antonio Spiga (beneficiado de la catedral y procurador de la parroquia de Selargius) con los maestros picapedrers Michele Pinna, Giacomo Cocodi y Francesco Pinna para la construcción del presbiterio de la parroquia de Selargius. Para su realización, los maestros debían seguir el diseño proporcionado por los comitentes, que consistía en una cúpula octagonal (vujt ovada), que habían visto en un "llibre de trassas del offici de picapedrer" 47 . En este caso, el modelo pudo haberse extraído de un manual de cantería como el manuscrito del mallorquín Joseph Gelabert (1652 ca.) ${ }^{48}$, donde se dan cita soluciones constructivas propias de la tradición gótica junto a soluciones clasicistas como el "ciborio" con cúpula o molduras y repertorios decorativos al romano, sirviendo al mismo tiempo como instrumento técnico para el maestro y como catálogo de soluciones para los comitentes ${ }^{49}$.

El paso de la estructura cuadrada del ábside al octógono de la cubierta se realizó mediante bóvedas de peu de llantia ${ }^{50}$, un recurso que, como ya hemos mencionado anteriormente se encontraba presente en Cerdeña anteriormente, y que a partir de este momento se erigió en alternativa para configurar el paso del cuadrado al octágono en las construcciones con cúpula del Seiscientos ${ }^{51}$.

\footnotetext{
${ }^{44}$ Entre los ejemplos que cabe destacar encontramos la cubierta del ábside de la iglesia de Santa María de Valverde en Iglesias, realizada en 1592 por Antioco Spada, o la iglesia parroquial de Mandas, concluida en 1605 por Michele Valdabella y Giontinio Pinna. Aldo Pillitu, "Un monumento tardogotico sardo: la chiesa parrocchiale di Sant'Ambrogio in Monserrato", Studi Sardi, XXIX, (1991), pp. 405-425, espec., p. 420, nota 50 .

45 Marcello Schirru, "I sistemi voltati nelle architetture religiose della Sardegna tra il Cinque ed il Seicento: tecniche costruttive e varianti estetiche", Lexicon. Storie e architeture in Sicilia e nel Mediterraneo, 18, (2014), pp. 81-87, espec. pp. 86-87, documento 3.

46 Nobile, "Volte in pietra. Alcune rifessioni...", p. 29.

47 Marcello Schirru, "I sistemi voltati nelle architetture religiose...", pp. 86-87, documento 3.

48 Enrique Rabasa Díaz, El manuscrito de cantería de Joseph Gelabert titulado "Vertaderas traçes del art de picapedrer": transcripción, traducción, anotación e ilustración del texto y los trazados, (Madrid: Col.legi oficial d'arquitectes de les Illes Balears. Fundación Juanelo Turriano, 2011).

${ }^{49}$ La comparación con el manuscrito de Gelabert ha sido propuesta por: Giammusso, "Il Convento di...", p. 259.

50 "...quatre capelletes en les reconades las quals seran de una clau cascuna quals serviran per tornar con circol rodo ahont carregara la cupula", Schirru, "I sistemi voltati...", p. 87, documento 3.

${ }^{51}$ Nobile, "Volte in pietra. Alcune rifessioni...", p. 26.
} 
La solución empleada en el presbiterio de Selargius ha permitido revisar algunas construcciones que habían sido datadas y atribuidas erróneamente, sobre todo, debido a la falta de información que se tenía sobre ellas. Muchos de los ejemplos de estructuras con cúpula que se difundieron en Cagliari y en la zona centro-meridional de Cerdeña a partir de 1607, en capillas privadas o en ampliaciones del presbiterio, toman como referencia el modelo del presbiterio de Selargius. La creación de un espacio cubierto con cúpula situado por detrás del ábside fue frecuente también en algunas iglesias valencianas a partir de 1631, cuando el arzobispo valenciano fray Isidoro Aliaga estableció en el sínodo la aplicación de uno de los decretos surgidos tras el Concilio de Trento que tenía como finalidad la perfecta celebración de la comunión sin perturbar los Oficios Divinos ni causar distracción ${ }^{52}$. Este decreto sinodal dio lugar a la construcción de las denominadas "capillas de comunión", las cuales debían situarse por detrás del presbiterio. Tal y como

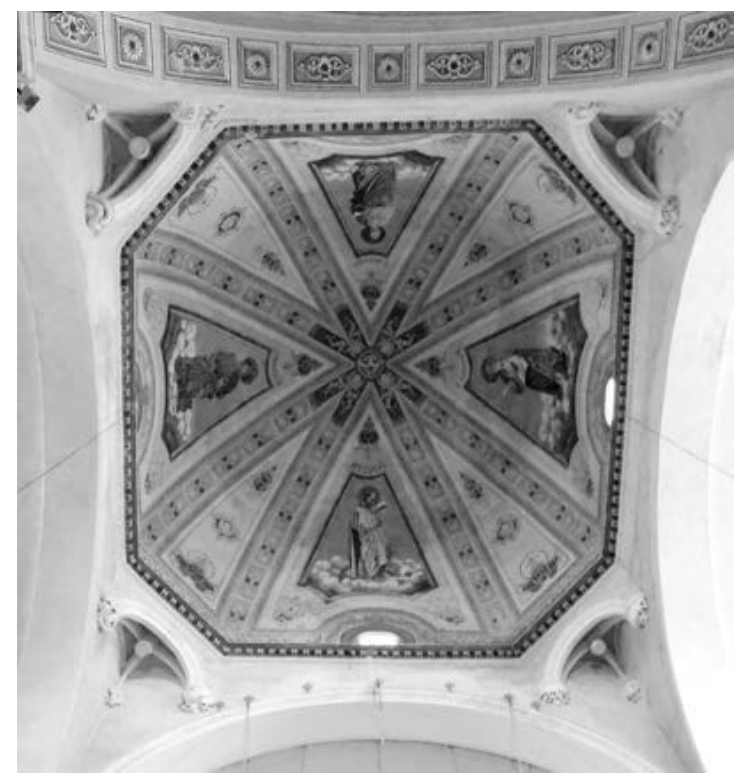

Fig. 9. Selargius (Cagliari), iglesia parroquial de Santa María Assunta. Cúpula del presbiterio (Foto: Marcello Schirru)

recoge el sínodo de Aliaga, estas capillas debían decorarse y labrarse con especial adorno. Es por ello por lo que se eligió la cúpula para cubrir estos espacios, dotándolos de magnificencia. Aunque no disponemos de información documental que lo confirme con seguridad, resulta muy atractiva la posibilidad de que en Cerdeña se siguiese una estrategia similar al caso valenciano.

52 Alfonso Rodríguez G. de Ceballos, "Liturgia y configuración del espacio en la arquitectura española y portuguesa a raíz del Concilio de Trento", Anuario del Departamento de Historia y Teoría del Arte, 3, (1991), pp. 43-52, espec., p. 45; En el sínodo se estableció que el Santísimo Sacramento se reservase habitualmente en el tabernáculo del Altar Mayor pero que, para la distribución de la comunión, a fin de que no entorpeciese la celebración de los oficios divinos en la capilla mayor, se construyese en adelante una capilla diferente situada, a ser posible, en el ábside por detrás de aquella. 
Así ocurrió con el presbiterio de la capilla de la Virgen del Rosario en la iglesia de Santo Domingo de Cagliari, realizado entre 1627-2953, la capilla de la Virgen del Carmen en la iglesia del Carmen y la ampliación del presbiterio de la iglesia del Sagrado Monte de Piedad de la misma ciudad ${ }^{54}$. Cabe destacar entre estos ejemplos, el maravilloso espacio comúnmente denominado "archivietto" de la catedral de Oristano, construido a partir de $1622^{55}$ por los maestros picapedrers Francesco Orrú y Melchiorre Uda, que se compone de una cúpula nervada con bóvedas de peu de llantia y elementos de conexión con motivos decorativos en forma de concha que permiten el paso del octógono a la circunferencia, un elemento que en la Península ibérica acabó sustituyendo a las bóvedas de peu de $/ l a n t i a^{56}$ [fig. 10]. Ejemplos más tardíos como la capilla de San Antíoco situada en el brazo izquierdo del transepto de la catedral de Iglesias siguieron en un primer momento la misma configuración. El proyecto inicial del 9 de noviembre de 1656 preveía seguir el modelo de la capilla del Rosario de la iglesia de Santo Domingo de Cagliari, pero con un arco de ingreso mayor respecto al citado modelo ${ }^{57}$. El proyecto se vio interrumpido seguramente por la llegada de la peste a la ciudad y volvió a retomarse entre el 3 de marzo de 1668 y el 14 de marzo de $1670^{58}$. Nuevamente, el proyecto no pudo concretarse y el 12 de diciembre de 1679 Giovanni Domenico Spotorno, Francesco Orrú ${ }^{59}$ e Ignacio Sanna eran contratados para llevar a cabo la capilla según un proyecto de Spotorno, aunque esta vez la capilla sí fue realizada, el 27 de noviembre de 1680 se vino abajo por causas desconocidas. Finalmente, la capilla fue realizada tal y como se encuentra actualmente por el genovés Domenico Spotorno a partir de 1681 .

La llegada de artistas - y de modelos -foráneos como Domenico Spotorno, permitió ensayar nuevas fórmulas ornamentales como sucede en la capilla de San Antonio en la iglesia de San Francisco de Iglesias, donde la capilla, está realizada mediante una cúpula ochavada tratando de obtener un resultado de apariencia eminentemente estructural, mediante la aplicación de elementos de carácter arquitectónico y figurativo.

\footnotetext{
53 Tradicionalmente atribuido a los maestros Gaspare y Michele Barrai, a través de un contrato de fábrica de 1580 publicado por Carlo Aru en 1930, donde los dos maestros se comprometían a construir en la iglesia de Santo Domingo la capilla del mercader Giovanni Antonio Carta; Carlo Aru, "Un primo documento per la storia dell'architettura in Sardegna nel Rinascimento", Mediterranea, 12, 4, (1930), pp. 1-15, espec. 14-15. Recientemente, se ha identificado el ambiente en el cual trabajaron los Barrai. Se trataba de una primera versión de la capilla, realizada con un ambiente rectangular cubierto con dos bóvedas de crucería, mientras que el coro de la capilla fue construido solamente entre 1627-1629: Schirru, "I sistemi voltati..."; sobre el ambiente realizado por los Barrai: Federico Giammusso, "I Barrai, picapedrers cagliaritani della seconda metà del Cinquecento. Stato degli studi e nuove ipotesi", Lexicon. Storie e architetture in Sicilia e nel Mediterraneo, 19, (2014), pp. 78-82.

54 Schirru, "I sistemi voltati...".

55 Pulvirenti et al., Architettura tardogótica e d'infusso, pp. 236-237.

56 Nobile, "Volte in pietra. Alcune rifessioni...", p. 29.

57 Agradezco a Silvia Medde las referencias sobre el documento que se encuentra en: Archivio del Capitolo della Cattedrale de Iglesias presso I'Archivio Storico Diocesano di Iglesias, no 4, sedute del 29 aprile 1655 al 31 dicembre 1681; El primer proyecto, fue encargado a Pere Antiogo Cucuro junto a otros picapedrers. 58 El noble Antioco de Carcassona pide al capítulo de Iglesias permiso para construir la capilla de Sant'Antioco, encargando del proyecto a Pere Antiogo Cucuro, Pietro Carta y Giuseppe Passiu.

${ }^{59}$ Es interesante destacar la presencia de un Francisco Orrú en los trabajos de la capilla de Sant'Antioco. Recordemos que un Francesco Orrú construyó junto con Melchiorre Uda el "archivietto" de Oristano.
} 
La difusión de las cúpulas a partir del siglo XVII en Cerdeña muestra la dinámica que se generó en la arquitectura religiosa sarda de la época, donde se llegaron a crear originales soluciones propias, gracias a la participación de comitentes pertenecientes al clero o surgidos en el clima del reformismo de la segunda mitad del siglo XVI, y a maestros que supieron interpretar las ambiciones de los comitentes, valiéndose de los conocimientos técnicos necesarios para plasmarlas. No se trató, en ningún caso, de una mera práctica constructiva o de una respuesta a exigencias funcionales, sino que, tal y como ha demostrado Marco Rosario Nobile, detrás de cada elección cons-

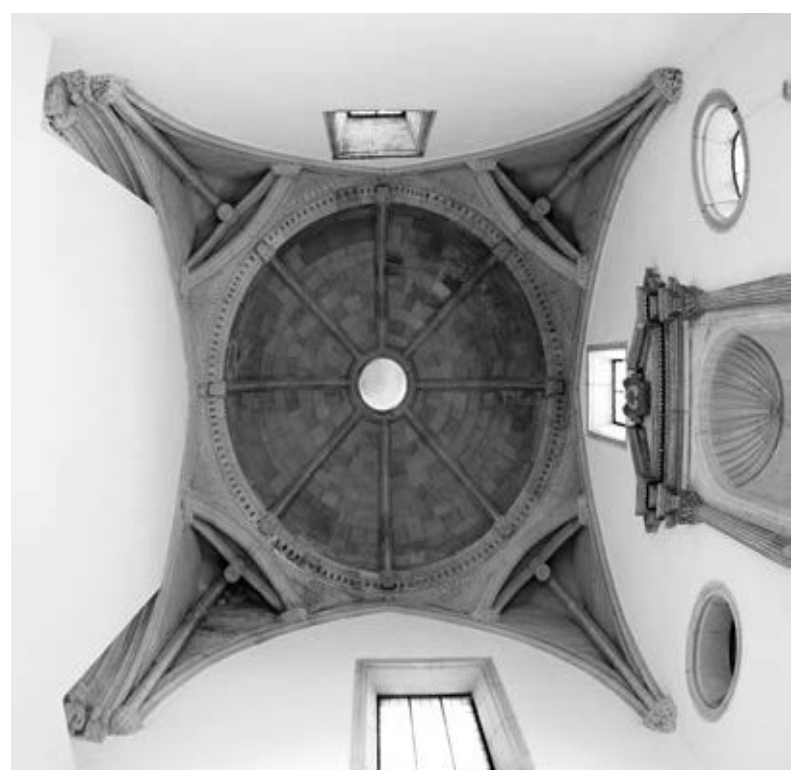

Fig. 10. Oristano. Catedral. Archivietto

tructiva existía la misma "retorica e autorappresentazione di quanto se ne possa trovare in un capitello ionico o una base vitruviana" ${ }^{60}$. El resultado obtenido fue una arquitectura que difícilmente podemos encuadrar en las categorías convencionales de gótico o renacentista, sino que la definición resulta verdaderamente complicada. Las razones por las que persistieron los sistemas constructivos tradicionales fueron probablemente más complejas de lo que pensamos, y estaban estrechamente ligadas a un modo diferente de entender y concebir las estructuras tradicionales, ya que a partir de los años sesenta estos sistemas se consideraban totalmente actualizados. Los elementos de tradición gótica como bóvedas de crucería o bóvedas de peu de Ilantia fueron probablemente entendidos como clásicos, y por lo tanto capaces de sostener cúpulas ochavadas o de trabajarse al romano ${ }^{61}$. Para los maestros y comitentes de la época, este proceso de reinterpretación fue absolutamente consciente y racional, y no como fruto de un periodo dubitativo a la hora de

${ }^{60}$ Nobile, "Volte in pietra. Alcune rifessioni...", p. 13.

${ }^{61}$ Schirru, "I sistemi voltati...", p. 56. 
elegir los modelos empleados, ni denominar a los maestros como incapaces para trabajar con las nuevas técnicas constructivas.

En este sentido no podíamos estar más de acuerdo con las observaciones realizadas por Eduard Mira sobre la mayor perdurabilidad en el tiempo de los procesos constructivos que de los lenguajes arquitectónicos, a los que se recurría a menudo como simples formas decorativas por lo que la comparación morfológica entre edificios en ocasiones no es suficiente ${ }^{62}$. En este sentido, la arquitectura realizada en Cerdeña entre mediados del siglo XVI y la primera mitad del siglo XVII muestra perfectamente como a menudo podían tomarse como ejemplo y ser propuestos como totalmente válidos modelos realizados en otras épocas y en otros lugares.

62 Eduard Mira, "Una arquitectura gótica mediterránea: estilos, maneras e ideologías", en Una arquitectura gótica mediterránea, dir. Eduard Mira, Arturo Zaragozá, (Generalitat Valenciana, Conselleria de Cultura i Educació, Valencia, 2003), pp. 25-103. 
Bibliografía:

Angius 1849: Vittorio Angius, "Sassari", en Dizionario geografico storicostatistico-commerciale degli Stati di S.M. il Re di Sardegna, dir. Goffredo Casalis, (Torino, 1849).

Aru 1930: Carlo Aru, "Un primo documento per la storia dell'architettura in Sardegna nel Rinascimento", Mediterranea, 12, 4, (1930), pp. 1-15.

Bermejo 2016: Eloy Bermejo, La catedral de Sassari y la arquitectura religiosa en Cerdeña entre los siglos XVI y XVIII, Tesis de Doctorado en Analisi, rappresentazione e pianificazione delle risorse territoriali, urbane, storichearchitettoniche e artistiche XXV Ciclo, Università degli Studi di Palermo Universidad de Zaragoza, 2016.

Bustamante y Marías 1982: Agustín Bustamante y Fernando Marías, "La catedral de Granada y la introducción de la cúpula en la España del Renacimiento", Boletín del Museo Camón Aznar, VIII, (1982), pp. 103-115.

Bustamante y Marías 1985: Agustín Bustamante y Fernando Marías, "La sombra de la cúpula de El Escorial", Fragmentos, 4-5, (1985), pp. 46-63.

Cadinu 2012: Marco Cadinu, "Il rudere della chiesa di Santa Lucia alla Marina di Cagliari. Architettura, archeologia e storia dell'arte per il recupero di un luogo della città medievale", ArcheoArte. Rivista elettronica di archeologia e arte, Supplemento al no 1, (2012), pp. 543-575.

Carbonell i Buades 2008: Marià Carbonell i Buades, "De Marc Safont a Antoni Carbonell: la pervivencia de la arquitectura gótica en Cataluña", Artigrama, 23, (2008), pp. 97-148.

Casu 2003: Pietro Casu, Vocabolario sardo logudorese - italiano, (Nuoro: Ilisso, 2003).

Delogu 1988: Raffaello Delogu, L'architetura del Medioevo in Sardegna, (Sassari: Carlo Delfino editore), 1988.

Fara 1992: Giovanni Francesco Fara, In Sardiniae Chorographiam, ed. Enzo Cadoni, (Sassari: Gallizzi, 1992).

Fullana 2005: Miquel Fullana, Diccionari de l'art i dels oficis de la construcció, (Palma de Mallorca: Institut Moll, 2005).

Garofalo 2008: Emanuela Garofalo, "Fra Tardogotico e Rinascimento: la Sicilia sud-orientale e Malta", Artigrama, 23, (2008), pp. 265-300.

Garofalo 2010: Emanuela Garofalo, "Le architetture della Compagnia di Gesù in Sardegna (XVI-XVIII secolo)", en La arquitectura jesuítica, coords: María Isabel Álvaro Zamora, Javier Ibáñez Fernández y Jesús Criado Mainar, (Zaragoza, Universidad de Zaragoza, 2010), pp. 141-192.

Garofalo 2012: Emanuela Garofalo, "La costruzione di un monumento tra Controriforma e tradizione gotica: la Chiesa dei Gesuiti a Sassari", en AID Monuments. Conoscere Progettare Ricostruire, (Perugia, Roma, 2012), pp. 143-15. 
Garofalo 2015: Emanuela Garofalo, "New architectural models and building tradition, a dialogue in early modern Sardinia. The Jesuit church in Sassari", International Journal of Architectural Heritage, 9, (2015), pp. 143-156.

Giammusso 2014: Federico Giammusso, "I Barrai, picapedrers cagliaritani della seconda metà del Cinquecento. Stato degli studi e nuove ipotesi", Lexicon. Storie e architetture in Sicilia e nel Mediterraneo, 19, (2014), pp. 78-82.

Giammusso 2015: Federico María Giammusso, Il Convento di San Domenico a Cagliari, Tesis de Doctorado en Storia dell'architettura e conservazione dei beni architettonici XXIV Ciclo, Università degli Studi di Palermo - Universidad de Zaragoza, 2015.

Giuffrè 1996: Maria Giuffrè, "Architettura in Sicilia nei secoli XV e XVI: le cappelle a cupola su nicchie fra tradizione e innovazione", Storia architettura, s.n., 2, (1996), pp. 33-48.

Ibáñez 2007: Javier Ibáñez, "Renacimiento a la francesa en el Quinientos aragonés", Artigrama, 22, (2007), pp. 473-511.

Ibáñez 2008: Javier Ibáñez Fernández, "La arquitectura en el reino de Aragón entre el gótico y el renacimiento", Artigrama, 23, (2008), pp. 39-95.

López Mozo 2013: Ana López Mozo, "La huella de El Escorial en las cúpulas españolas de finales del siglo XVI. El caso de la Capilla Cerralbo de Ciudad Rodrigo", Informes de la construcción, Extra-2, 65, (2013), pp. 95-109.

Marisa Porcu Gaias, Sassari. Storia architettonica e urbanistica dalle origini al '600, (Nuoro: Ilisso, 1996).

Mira 2003: Eduard Mira, "Una arquitectura gótica mediterránea: estilos, maneras e ideologías", en Una arquitectura gótica mediterránea, dir. Eduard Mira, Arturo Zaragozá, (Generalitat Valenciana, Conselleria de Cultura i Educació, Valencia, 2003), pp. 25-103.

Morales 1991: Alfredo J. Morales, "Sobre la Capilla Real de Sevilla y algunos de sus creadores", Archivo hispalense: Revista histórica, literaria y artística, 227, 74, (1991), pp. 185-196.

Morales 2012: Alfredo J. Morales, "La arquitectura jesuítica en Andalucía. Estado de la cuestión" en La arquitectura jesuítica, dir. María Isabel Álvaro Zamora, Javier Ibáñez Fernández, Jesús Criado Mainar, (Zaragoza, 2012), pp. 327-354.

Mossa 1951: Vico Mossa, Restauri nella Cattedrale di Sassari. Relazione letta in Duomo il 2 febbraio 1951, (Sassari-Gallizzi: edizioni Ichnusa, 1951). Mossa 1988: Vico Mossa, Architetture sassaresi, (Sassari: Carlo Delfino editore, 1988).

Nobile 2002: Marco Nobile, Un altro rinascimento. Architettura, maestranze e cantieri in Sicilia, 1458-1558, (Benevento: Hevelius, 2002), pp. 86-95. 
Nobile 2009: Marco Nobile, "Tra Gotico e Rinascimento: I'architettura negli Iblei (XV-XVI sec.)", en La storia ritrovata. Gli Iblei tra Gotico e Rinascimento, dir. Marco Nobile y Giuseppe Barone, (Comiso: Edizioni Salarchi), pp. 48-93.

Nobile 2012: Marco Nobile, "La cattedrale di Alghero. Note e ipotesi sul primo progetto", Lexicon. Storie e architetura in Sicilia e nel Mediterraneo, 14-15, (2012), pp. 26-27.

Nobile 2013: Marco Nobile, "Volte in pietra. Alcune rifessioni sulla stereotomia tra Italia meridionale e Mediterraneo in età moderna", en La stereotomia in Sicilia e nel Mediterraneo, dir. Marco Nobile, (Palermo: Edizioni Caracol, 2013), pp. 7-58.

Pillitu 1991: Aldo Pillitu, "Un monumento tardogotico sardo: la chiesa parrocchiale di Sant'Ambrogio in Monserrato", Studi Sardi, XXIX, (1991), pp. 405-425.

Rabasa Díaz 2011: Enrique Rabasa Díaz, El manuscrito de cantería de Joseph Gelabert titulado "Vertaderas traçes del art de picapedrer": transcripción, traducción, anotación e ilustración del texto y los trazados, (Madrid: Col.legi oficial d'arquitectes de les Illes Balears. Fundación Juanelo Turriano, 2011).

Rodríguez G. de Ceballos 1975: Alfonso Rodríguez G. de Ceballos, "La Capilla Cerralbo de Ciudad Rodrigo", Archivo Español de Arte, 190-191, 48, (1975), pp. $190-215$

Rodríguez G. de Ceballos 1991: Alfonso Rodríguez G. de Ceballos, "Liturgia y configuración del espacio en la arquitectura española y portuguesa a raíz del Concilio de Trento", Anuario del Departamento de Historia y Teoría del Arte, 3, (1991), pp. 43-52.

Schirru 2013: Marcello Schirru, "Forme e modelli architettonici tra la Spagna e la Sardegna del '500", ArcheoArte. Rivista elettronica di archeologia e arte, 2, (2013), pp. 281-298.

Schirru 2014: Marcello Schirru, "I sistemi voltati nelle architetture religiose della Sardegna tra il Cinque ed il Seicento: tecniche costruttive e varianti estetiche", Lexicon. Storie e architeture in Sicilia e nel Mediterraneo, 18, (2014), pp. 81-87.

Segni Pulvirenti y Sari 1994: Francesca Segni Pulvirenti y Aldo Sari, Architettura tardogótica e d'infusso rinascimentale, (Nuoro: Ilisso, 1994).

Sierra Delgado 2000: Ricardo Sierra Delgado, "La cúpula de la Sacristía Mayor de la Catedral de Sevilla: contexto y evolución en Andalucía" en Actas del Tercer Congreso Nacional de Historia de la construcción, dir. Amparo Graciani García (Sevilla: Instituto Juan de Herrera, 2000), pp. 1039-1048.

Sierra Delgado 2012: Ricardo Sierra Delgado, Diego de Siloé y la nueva fábrica de la Sacristía Mayor de la Catedral de Sevilla, (Sevilla: Universidad de Sevilla, 2012). 
Toda i Güell 2009: Eduard Toda i Güell, Cortes españolas de Cerdeña, (Cagliari: Arxiu de Tradicions de L'Alguer, 2009).

Zaragozá 2003: Arturo Zaragozá, "Arquitecturas del gótico mediterráneo" en Una arquitectura gótica mediterránea, dir. Eduard Mira, Arturo Zaragozá, (Generalitat Valenciana, Conselleria de Cultura i Educació, Valencia, 2003), pp. 107-196.

Recibido: $19 / 10 / 2017$

Aceptado: 30/10/2017 